\title{
The effect of microinjection of dimethyl sulfoxide into the rostral ventromedial medulla on swim stress-induced analgesia
}

\author{
S. Nazemi ${ }^{1}$, A. Shamsizadeh ${ }^{2}$, N. Haidari-Oranji ${ }^{3}$, N. Soleimani ${ }^{4}, \underline{\text { H. Azhdari Zarmehri }}^{5}$
}

\footnotetext{
${ }^{1}$ Cellular and Molecular Research Center, School of Medicine, Sabzevar University of Medical Sciences, Sabzevar, Iran

${ }^{2}$ Department of Physiology, Physiology-Pharmacology Research Center, Rafsanjan University of Medical Sciences, Rafsanjan, Iran

${ }^{3}$ Department of Physiology, School of Medicine, Zanjan University of Medical Sciences, Zanjan, Iran

${ }^{4}$ Physiology-Pharmacology Research Center, Rafsanjan University of Medical Sciences, Rafsanjan, Iran

${ }^{5}$ Department of Basic Sciences, Torbat Heydariyeh University of Medical Sciences, Torbat Heydariyeh, Iran
}

Corresponding Address: Hasan Azhdari Zarmehri, Department of Basic Sciences, Torbat Heydariyeh University of Medical Sciences, Torbat Heydariyeh, Iran

Tel: +98-51-5224697, Email hasan.azhdari@gmail.com

Received: 6 Sep 2017; Accepted: 31 Jan 2018

\section{Abstract}

Background: Dimethyl sulfoxide (DMSO) is an important solvent for compounds that used in pain research. Rostral ventromedial medulla (RVM) plays an important role in modulating nociception and stress-induced analgesia (SIA).

Objective: The aim of this study was to investigate the effect of DMSO administration into the RVM on SIA by using formalin test.

Methods: This experimental study was conducted on 27 Wistar male rats (200 \pm 30 gr) were randomly assigned to control, stress and stress+DMSO groups. Animals were placed in a water reservoir $\left(20 \pm 1^{\circ} \mathrm{C}\right)$ for 3 minutes to induce forced swimming stress. Stereotaxic surgery was performed to microinjection of DMSO $(0.5 \mu \mathrm{l}, 100 \%)$ into RVM. The pain behavior score was evaluated by subcutaneous injection of formalin $2 \%$ in the dorsal plantar region of hid paw.

Findings: The pain score of phase 1, interphase and phase 2 of formalin test in swim stress group decreased significantly in comparison to control group $(\mathrm{P}<0.001, \mathrm{P}<0.05, \mathrm{P}<0.001)$ respectively. In addition, the pain score of three phase of formalin test after DMSO injection in swim stress group decreased significantly in comparison to control and stress group $(\mathrm{P}<0.001, \mathrm{P}<0.05)$ respectively.

Conclusion: Also microinjections of DMSO into the RVM potentiate the swim stress analgesia. According to the analgesic effects of dimethyl sulfoxide, as well as its ability to potentiate stressinduced analgesia, DMSO should be used with caution as a solvent in pain studies.

Conclusion: Force swim stress induces analgesia in, and microinjections of DMSO into the RVM potentiate the swim stress analgesia. According to the analgesic effects of DMSO, as well as its ability to potentiate stress-induced analgesia, it should be used with caution as solvent in pain studies.

Keywords: Rostral ventromedial medulla, Dimethyl sulfoxide, Swim stress, Formalin test, Stressinduced analgesia

Citation: Nazemi S, Shamsizadeh A, Haidari-Oranji N, Soleimani N, Azhdari Zarmehri H. The effect of microinjection of dimethyl sulfoxide into the rostral ventromedial medulla on swim stressinduced analgesia. J Qazvin Univ Med Sci 2018; 21 (6): 4-13. 


\title{
اثر تزريق دىمتيل سولفوكسايد به بخش سرى شكمى - ميانى بصل النخاع بر بىدردى ناشى از تنش شنا
}

\author{
دكتر صمد ناظمى'، دكتر على شمسىزاده'، نيما حيدرى اورنجقى"، ندا سليمانى؛، دكتر حسن ازدرى زرمهرى
}

'مركز تحقيقات سلولى و مولكولى دانشكده يزشكى دانشعاه علوم يزشكى سبزوار، سبزوار، ايران

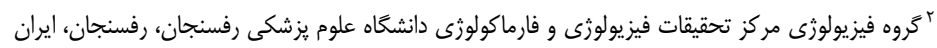

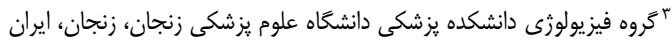

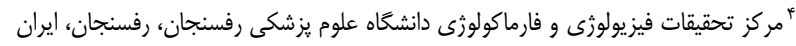

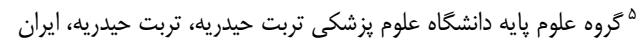

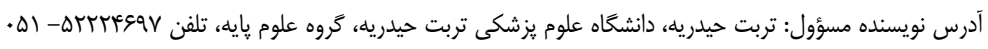

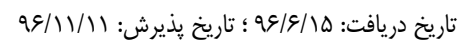

زمينه: دى متيل سولفو كسايد بهعنوان حامل بسيارى از تركيبات در مطالعات درد استفاده مىشود. بخش سرى شكمى - ميـانى بصـل النخـاع نقـش

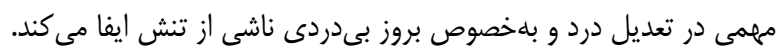

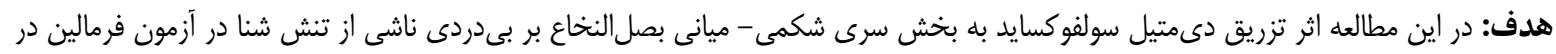
رتهاى نر مورد بررسى قرار كرفت.

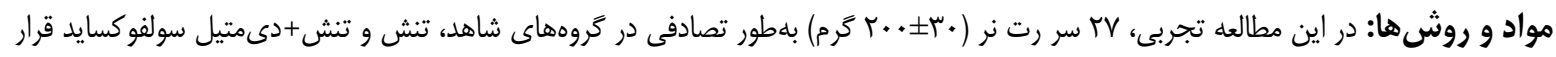

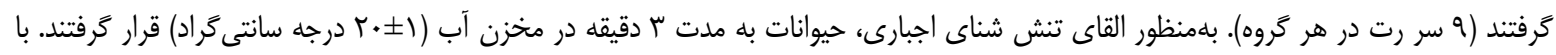

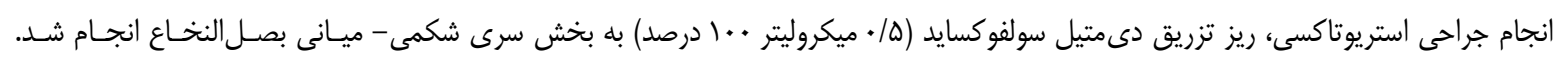

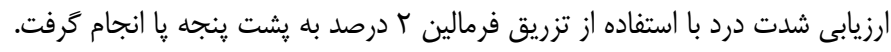

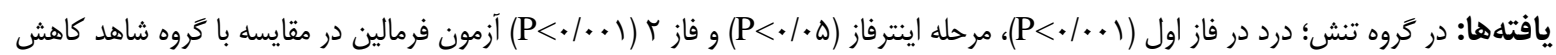

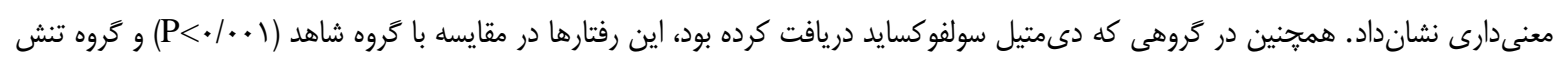

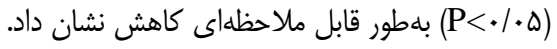

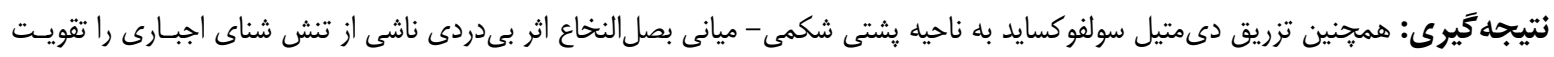

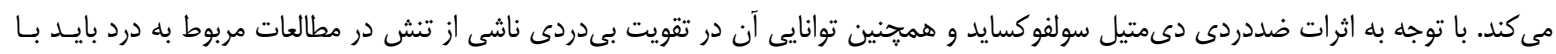
احتياط بيشترى به بنوان حلال استفاده شود.

كليدوازمها: بخش سرى شكمى - ميانى بصل النخاع، دىمتيل سولفوكسايد، آزمون فرمالين، تنش شنا، بـدردى ناشى از تنش

مزمن و مداوم موجب ايجاد يُردردى ناشسى از تنــش (Stress-induced hyperalgesia, SIH) تنش با تحريك مراكز مختلف قشــى و زيرقشـرى منـز

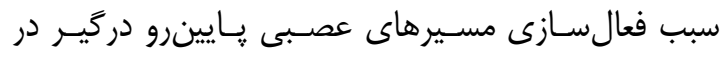

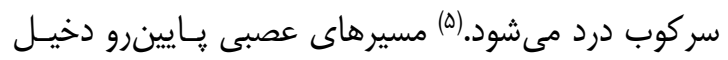

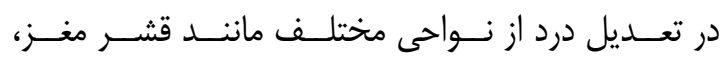

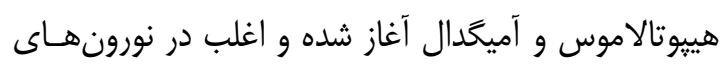

\section{|}

در سال هاى اخير مطالعات بالينى و آزمايشــاهى

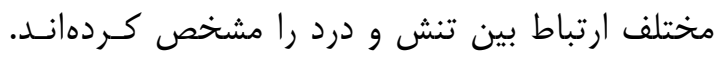

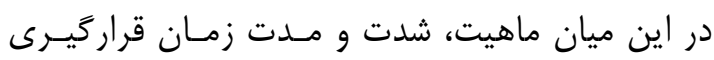
در معرض تنش، در ياسخ ايجاد شده بسيار تأثيرگـــار

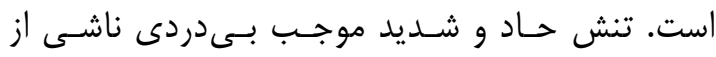
تنـــــ (Stress-induced analgesia, SIA) مى شود، در حالى كه قرار گرفتن در معرض تـنشهـاى 
اينحال دى متيل سولفوكسايد داراى اثرات سلولى وسيعى

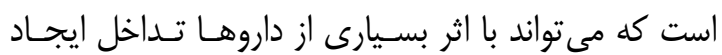

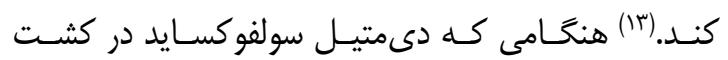

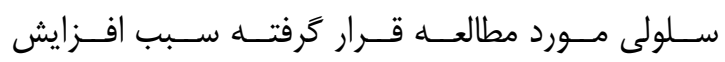
تحريكيـذيرى سـلول از طريـق افـزايش جريـان كانـال كلسيه، سديم و يا كلر شده است. اثرات رفتارى دى ملى متيـل

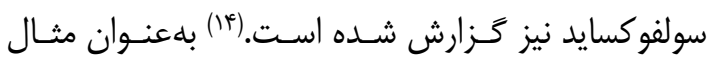

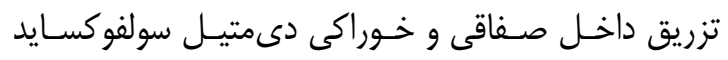

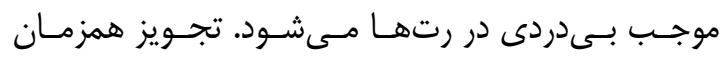

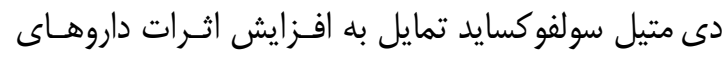

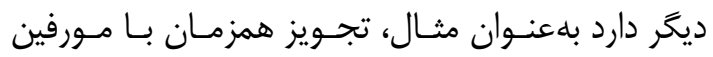

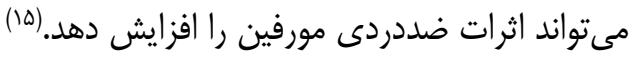

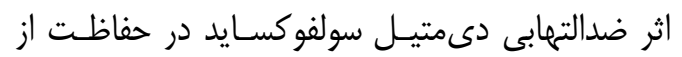

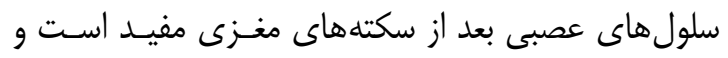

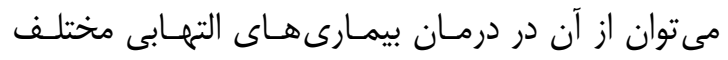

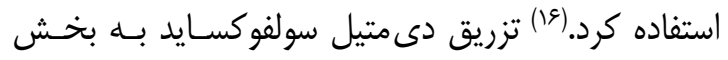

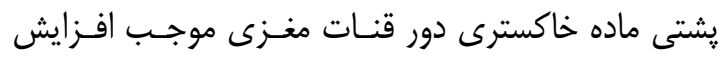

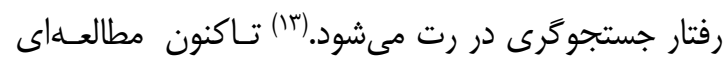

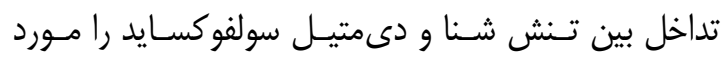

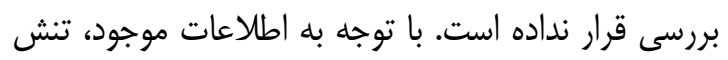

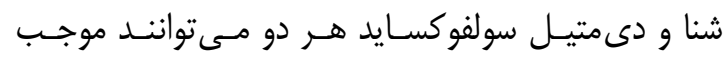

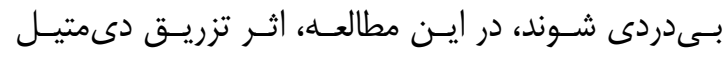

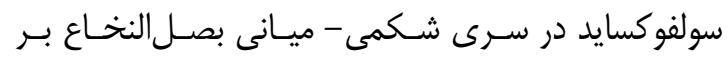

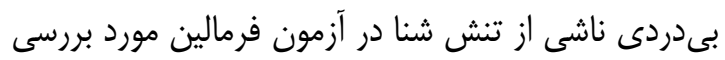

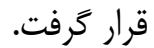

\section{2مواد و روشها:}

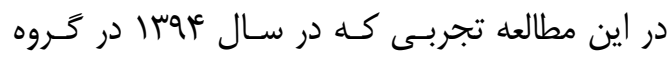

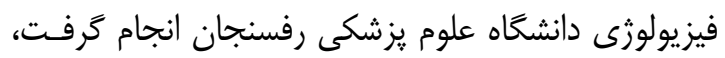

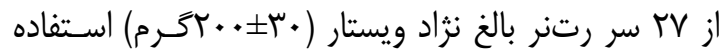

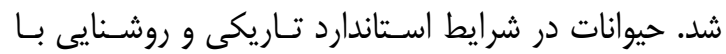

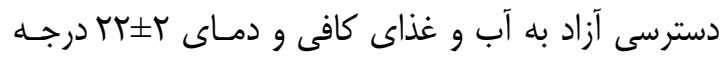

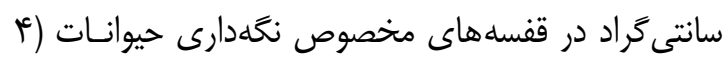
سر رت در هر قفس) نغخدارى شـدند. تمـامى آزمايشـات
شاخ خلفى نخاع كه مسئول انتقال ييـامهـاى مربـوط بــه

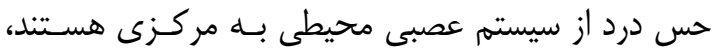

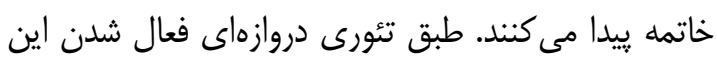

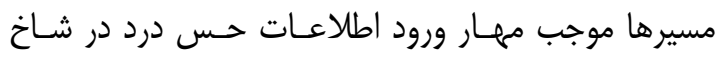

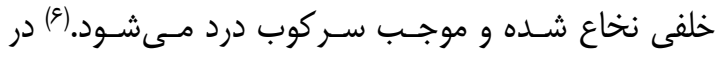

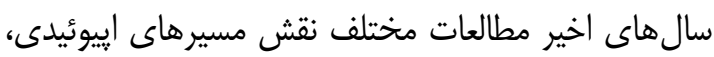

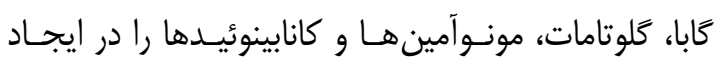

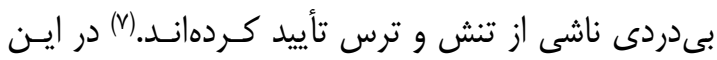

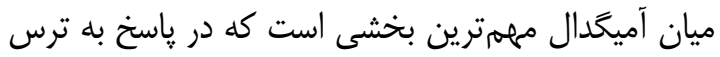

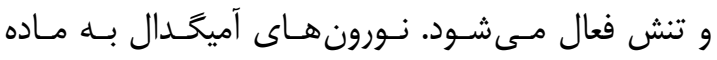

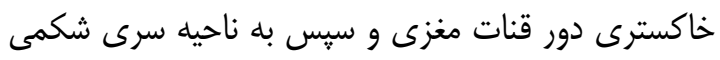

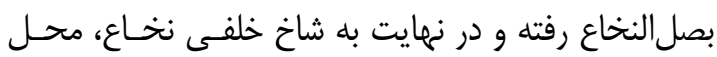

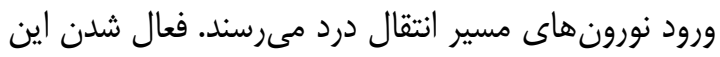

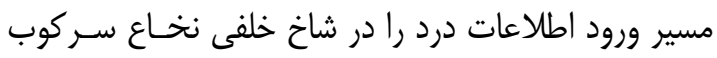

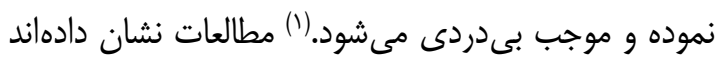

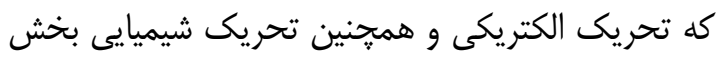

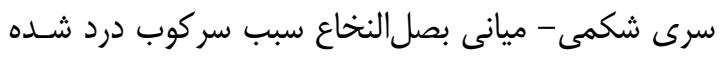

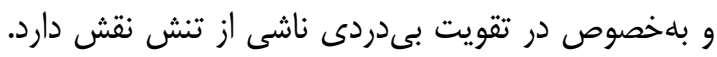

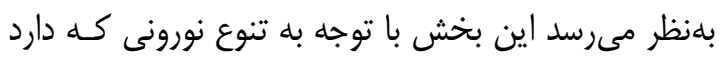

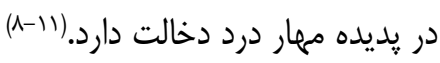

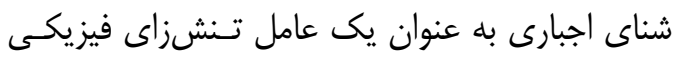

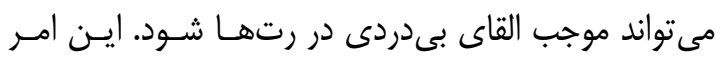

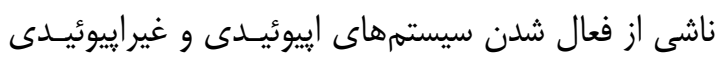

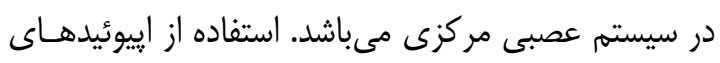

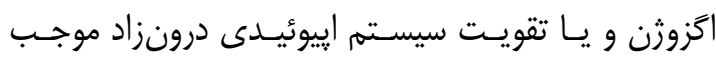

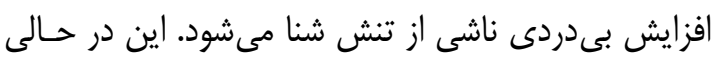

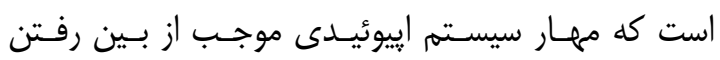

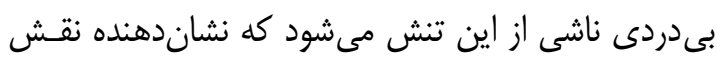

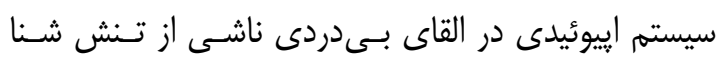

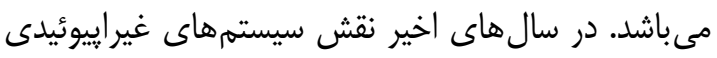

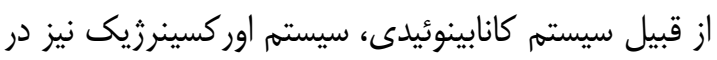
القاى بىدردى ناشى از تنش شنا به اثبات رسيده است.(IT)

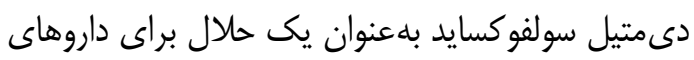

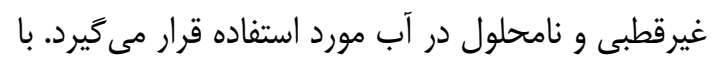


طويلتر از نوى كانول راهنما تهيه و از يك طرف به يك

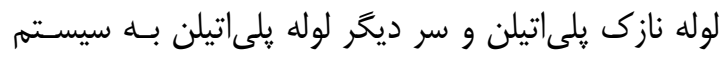

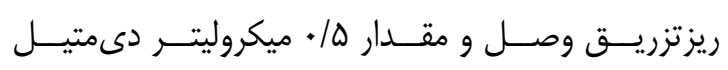

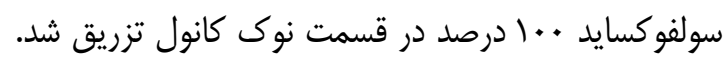
تزريق دىمتيل سولفوكسايد • ادقيقه قبل از انجام آزمون

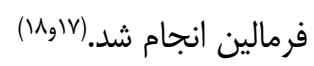

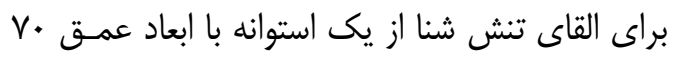

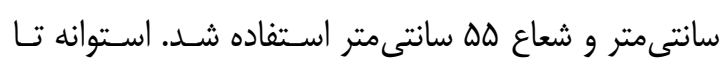

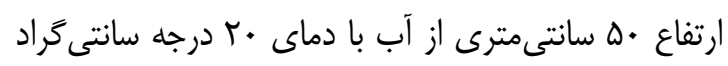

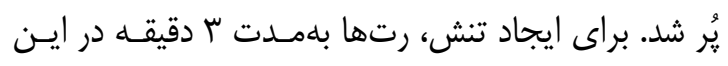

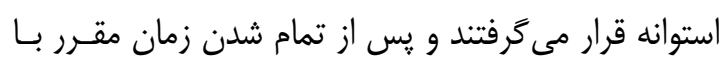

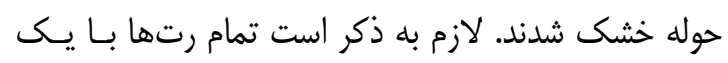

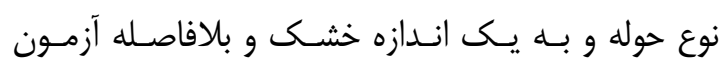

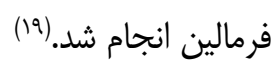

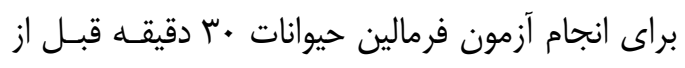

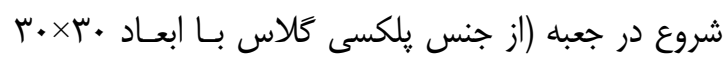

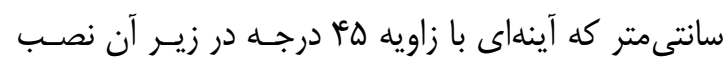
شده تا امكان ديدن مناسب حيوانات فراهم شود) قرار داده

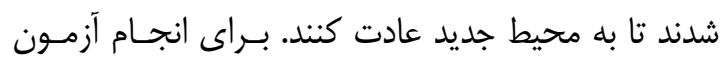

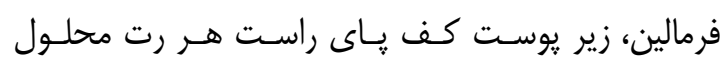

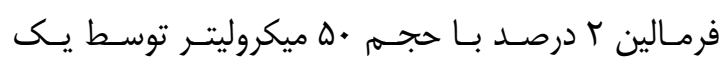

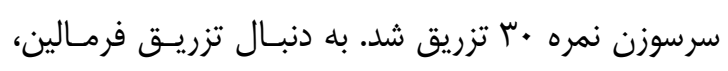

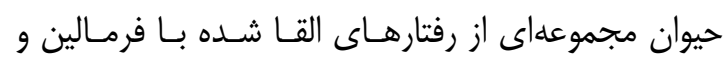

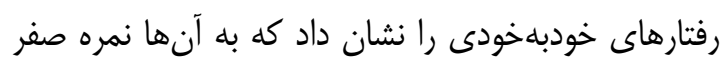

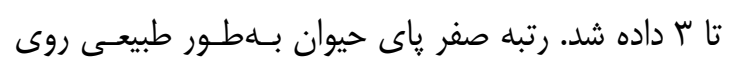

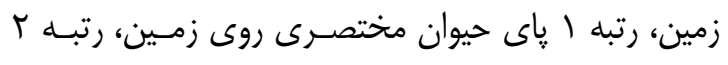

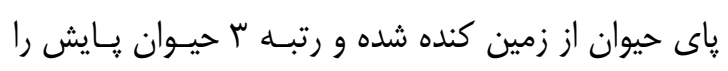

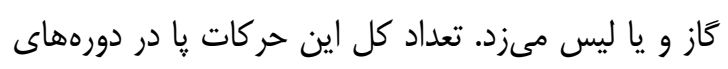

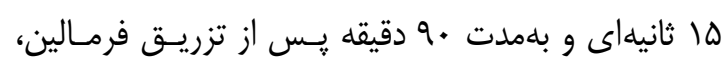

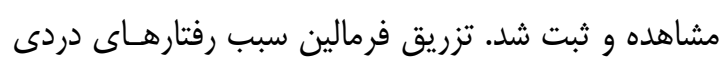

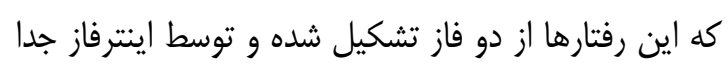

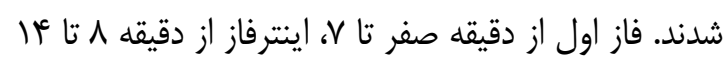

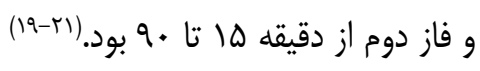

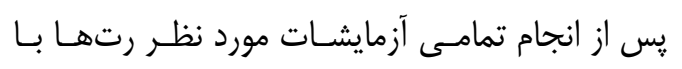

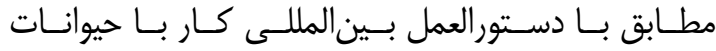

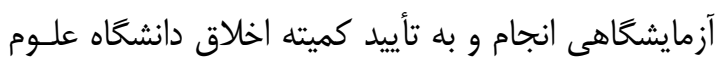

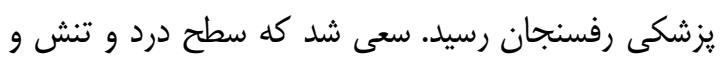
نيز تعداد رتهاى مورد استفاده را كاهش دهينمان رسئ.

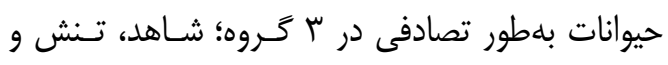

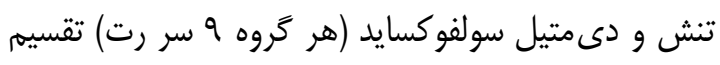

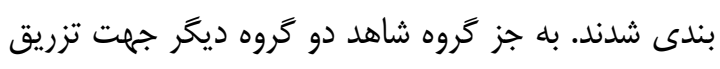

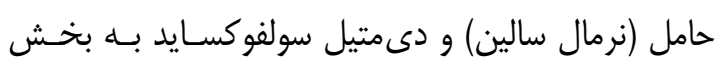

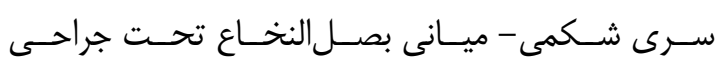
استريوتاكسى قرار كرفتند.

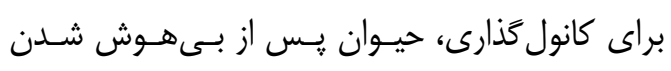

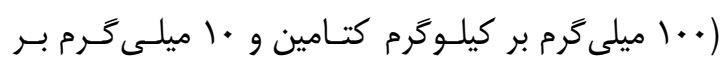

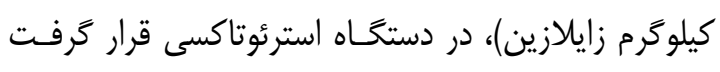

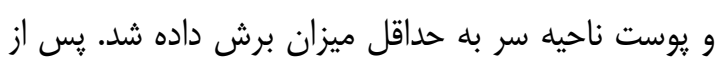
كنار زدن بافتهاى يوششى اطراف، نواحى بركَما و لامبدا

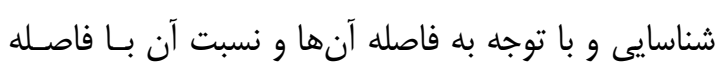

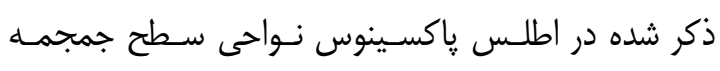
متعلق به هسته بخش سرى شكمى - ميانى بصـل النخـاع (AP:10.5-11, L:00, V:10.4)

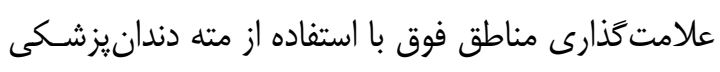

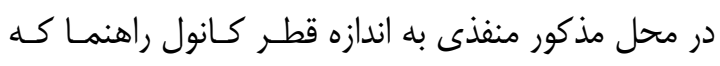

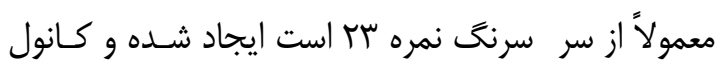

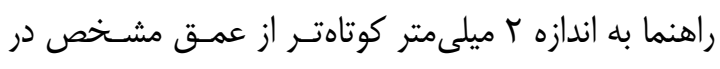

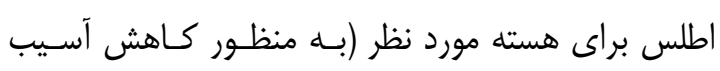

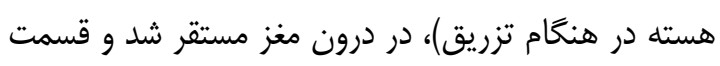

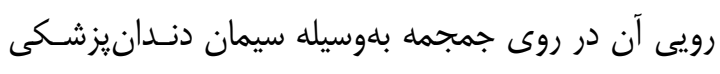

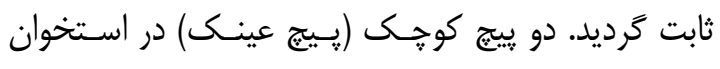

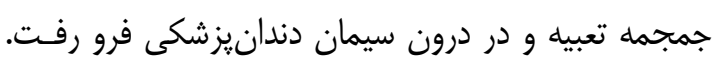

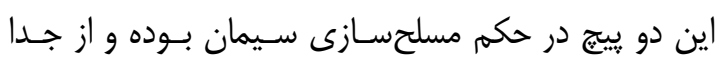

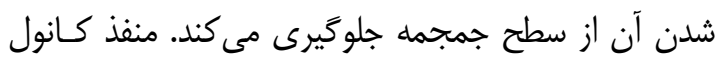

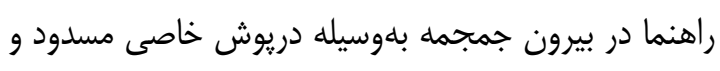

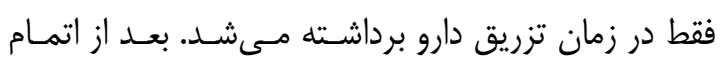

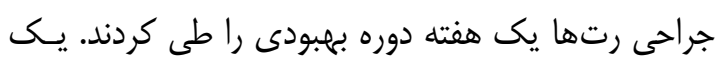

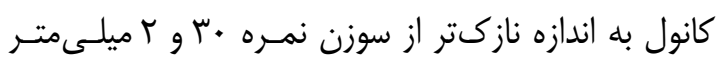


معنى دارى بين گروههاى شاهد، تنش و تـنش + دىمتيـل

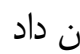

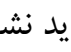
سولفو كس إك

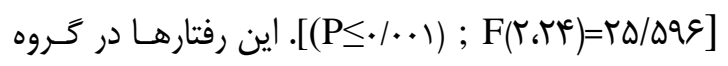

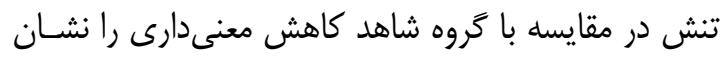

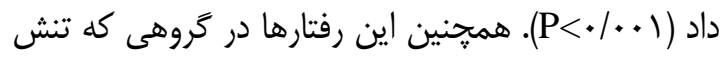

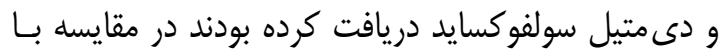

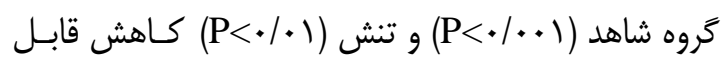
ملاحظهاى نشان داد. رفتارهاى درد ناشى از مرحله اينترفاز آزمون فرمـالين

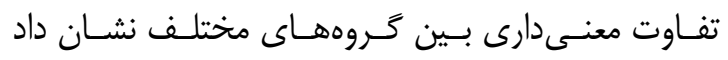

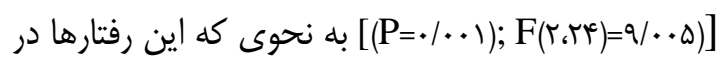

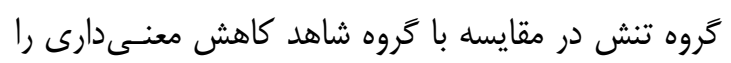

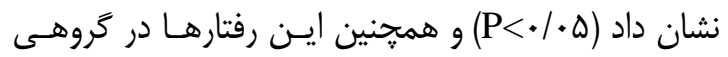

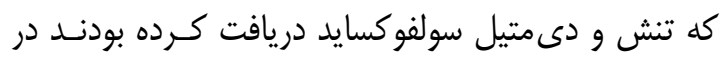

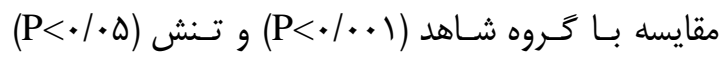
كاهش قابل ملاحظهاى نشان داد (شكل شماره r).
كتامين بى هوش و سِّ ه ميكروليتر رنخ متـيلن بلـو r

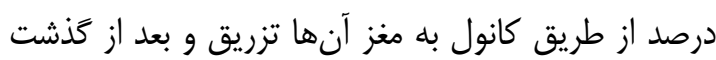

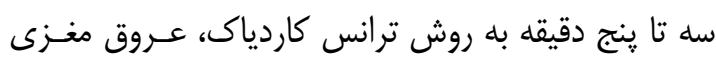

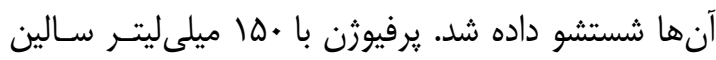

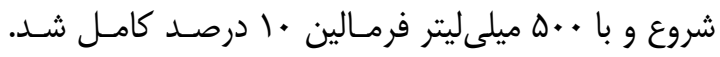

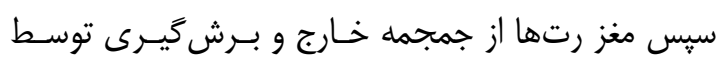

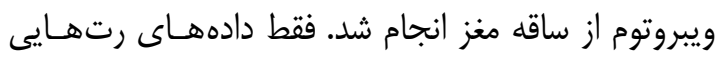

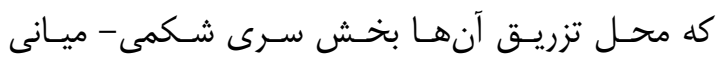

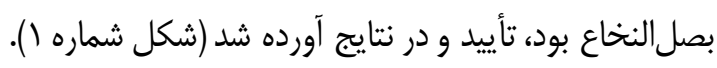

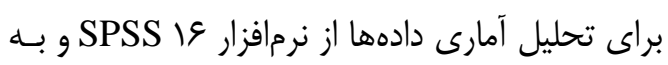

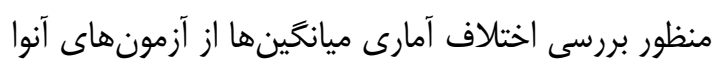

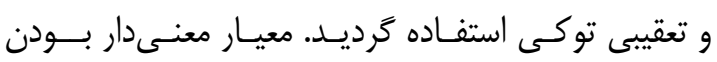

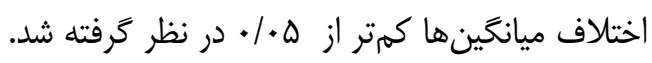

\section{يافتها:}

رفتارهاى درد ناشى از فاز اول آزمون فرمالين تفـاوت

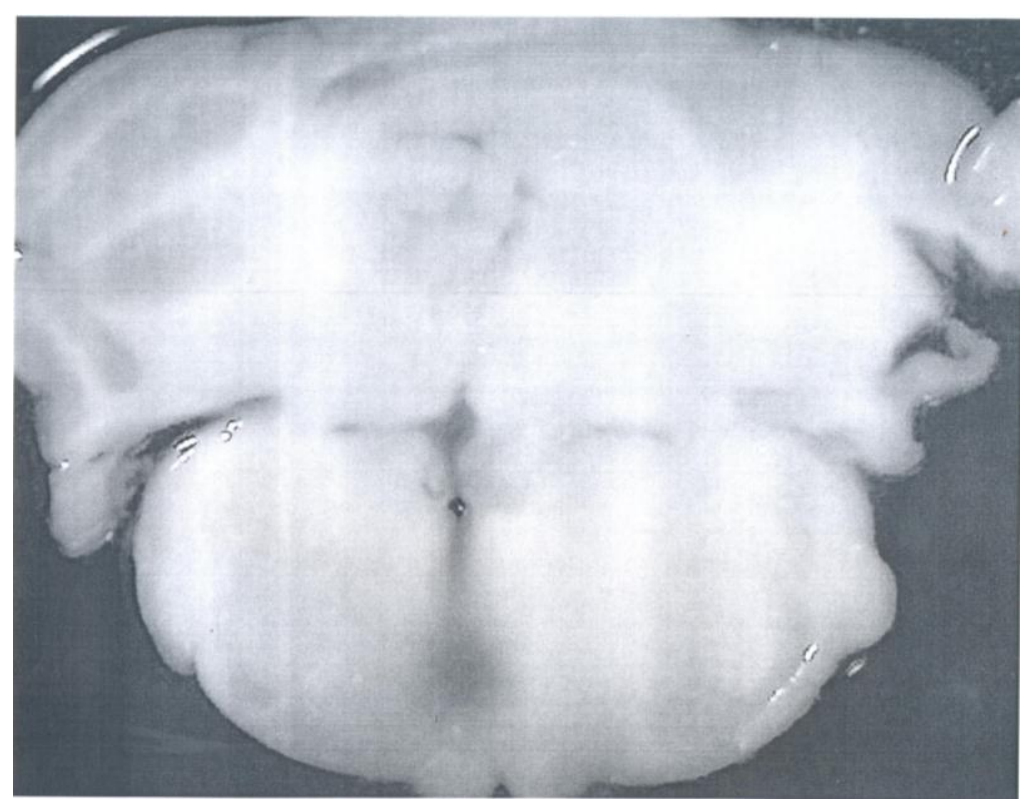

شكل ا - تأييد بافتشناسى براى نشان دادن محل تزريق در بخش سرى شكمى - ميانى بصل النخاع 


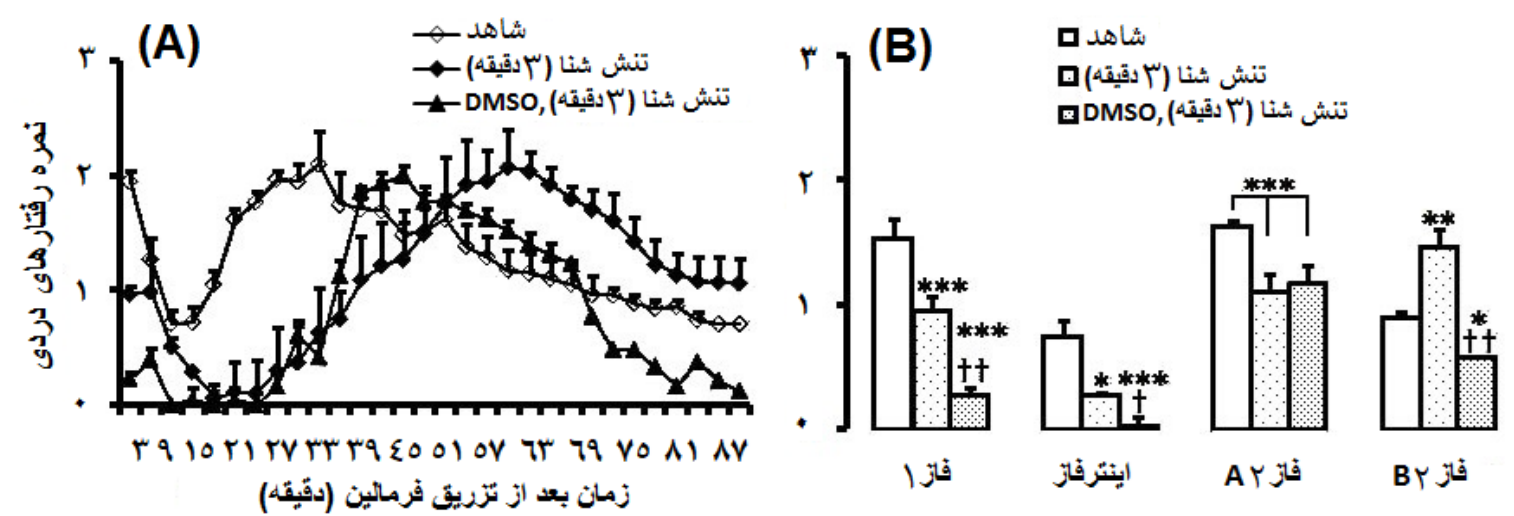

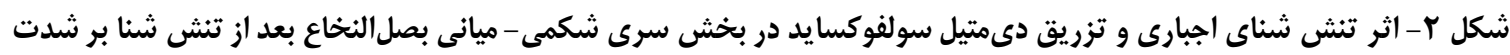

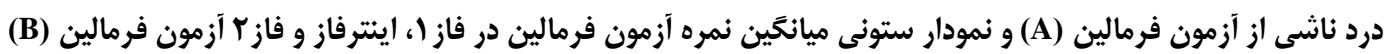

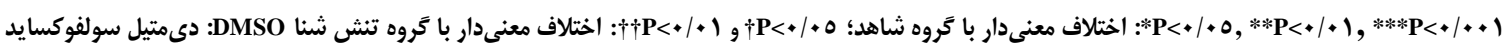

خاكسترى دور قنات مغزى سـبب بـىدردى مسىـود.(TF)

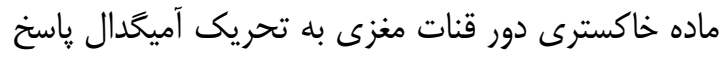
مىدهد و تحريك الكتريكى و تزريق مرفين در آميكـدال

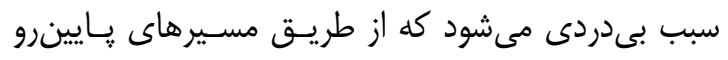

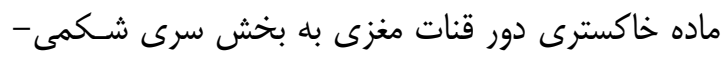

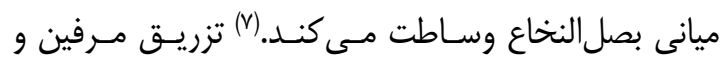
تحريــى الكتريكـى بخــش ســـى شـكمى - ميـانى

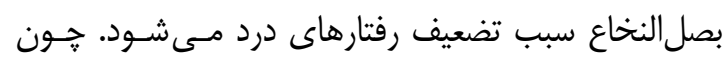

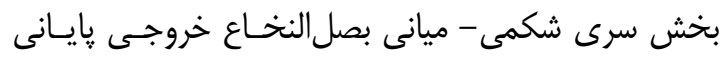

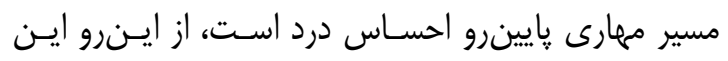

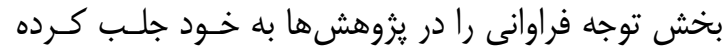
است. بخش سرى شـكمى - ميـانى بصـل النخـاع و مـاده

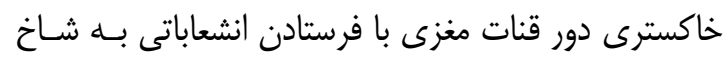

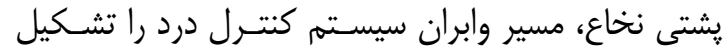
مى مهند. (rه) دى متيل سولفوكسايد داراى يكى طيف كسـتردهاى از

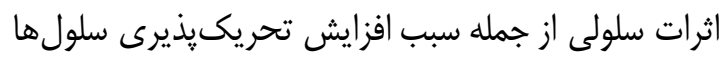

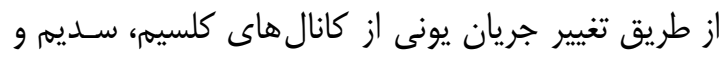

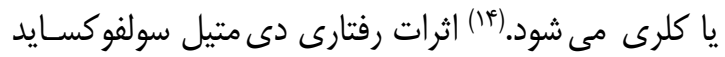

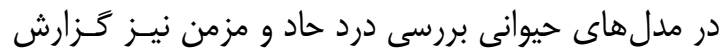

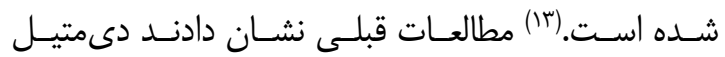

\section{نبحث و نتيجهَيرى}

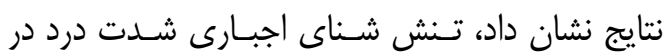

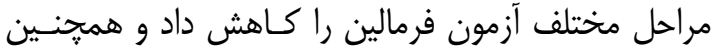

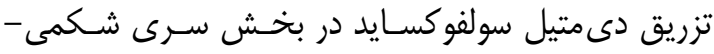

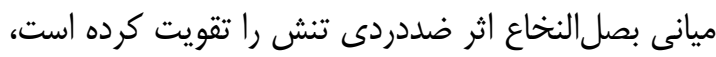
هر جند كه در فاز ب آزمون فرمالين اين اثر ديده نشد. تنش سبب فعالسازى جند سيستهم عصـبى دركيــر در سركوب درد مىشود. اين קديده بلعنوان بىدردى ناشى از

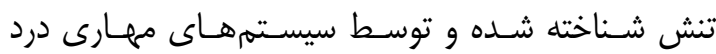

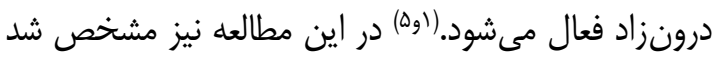
كه تنش شناى اجبارى توانسته است موجـب كـاهش درد درد در مراحل مختلف آزمـون فرمـالين شـود. مكانيسـمهــاى

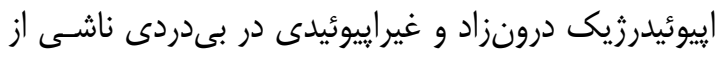

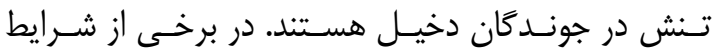
تنشزا، مهار سيسـته إييوئيـدرزيك درونزاد سـبب مهــار بىدردى ناشى از تنش مىشود، اما در برخى ديخًر از موارد

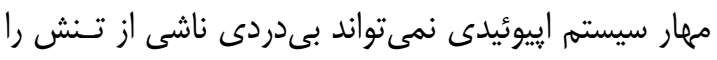
بلهور كامل سركوب كند كه نشان مىدهد مكانيسمهـاى غيراييوئيدى نيز ممكن است در بـروز بـىدردى ناشسى از

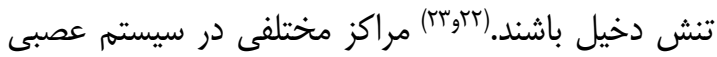

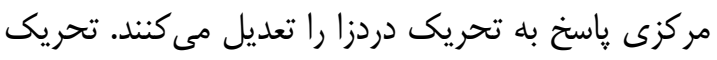
هييوتـالاموس يهلــويى از راه رلـه اطلاعـات بــه مــاده 
در نمره رفتارهاى درد مسىشـود، احتمـالاً مكانيسمهــاى

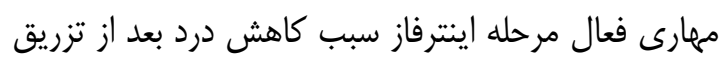

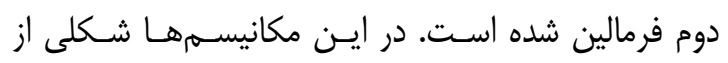

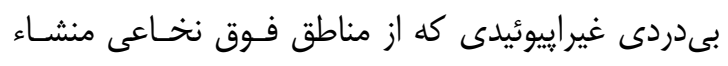

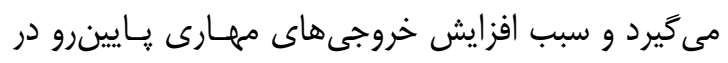

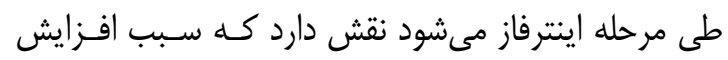

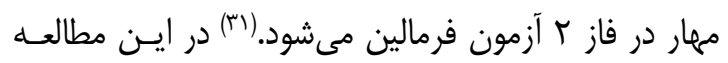

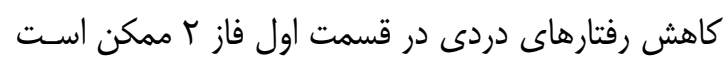

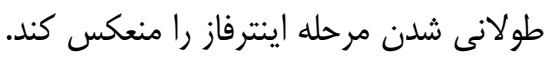

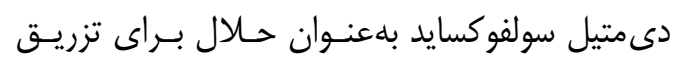

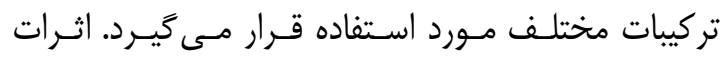

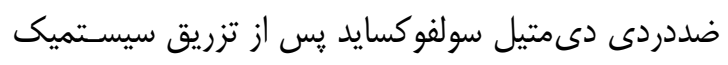

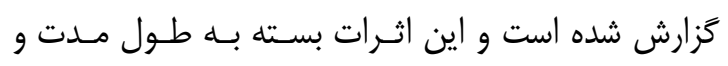

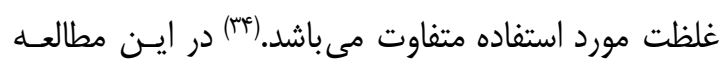

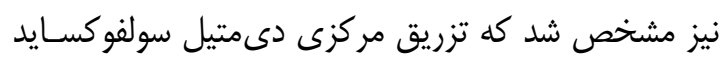

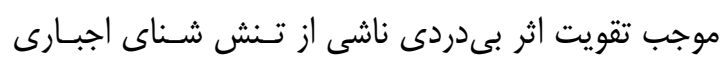

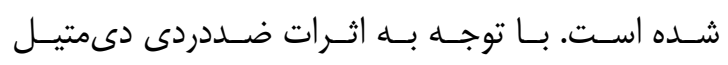

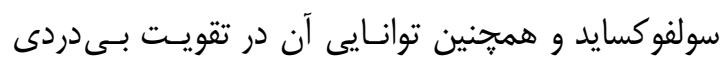

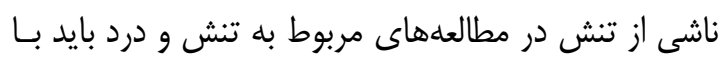

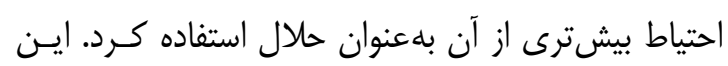

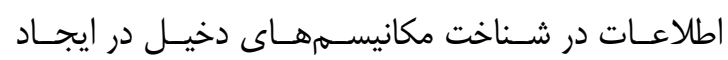

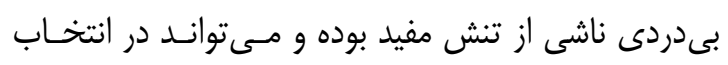

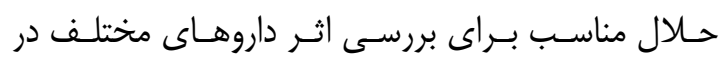
تحقيقات درد مفيد باشد.

\section{(رياس}

اين مقاله بخشـى از طــرح تحقيقـاتى مصـوب مركـز

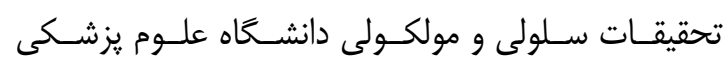

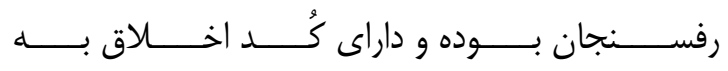
شماره RI.RUMS.REC.1394.191 از كميتـه اخـلاق دانشگاه علوم يزشكى رفسنجان مىباشد.

\section{مراجع:}

1. Butler RK, Finn DP. Stress-induced analgesia. Prog Neurobiol 2009; 88(3): 184-
سولفوكسايد سبب افزايش اثرات ضددردى مورفين شده و

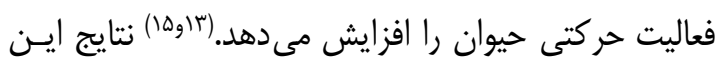

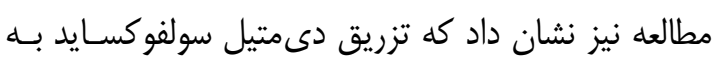

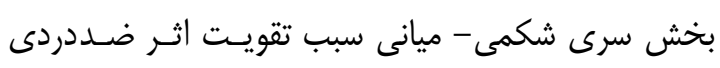

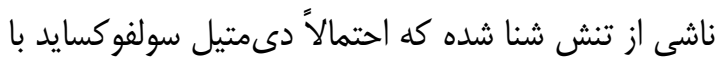

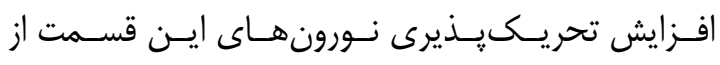

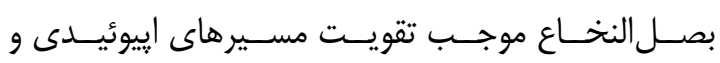
غير إييوئيدى دخيل در مهار درد شده است.

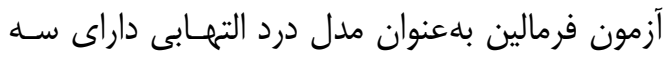

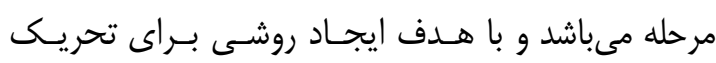

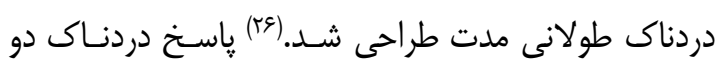

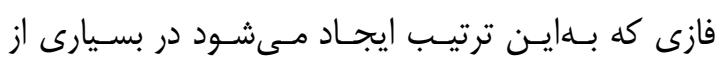

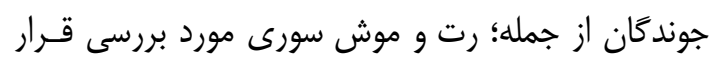

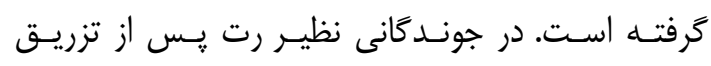

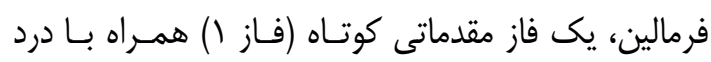

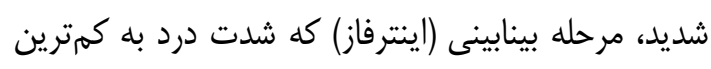

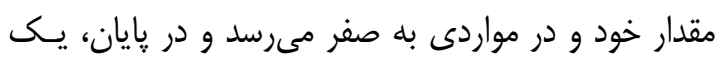

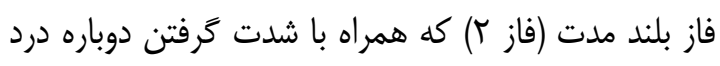

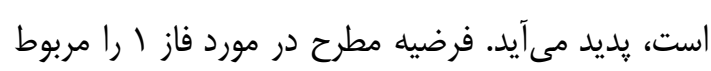

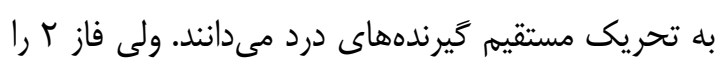

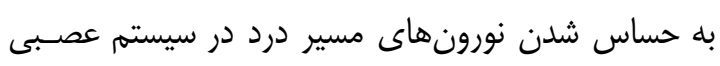

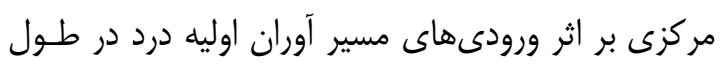

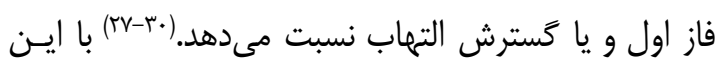

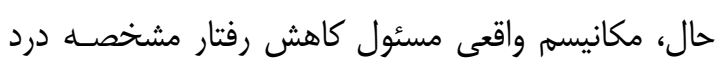

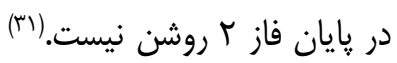

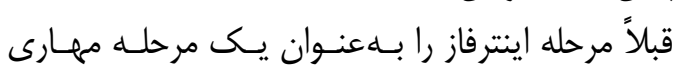
غيرفعال مىشناختند و شايد بهاين دليل مورد توجـهـ زيـاد

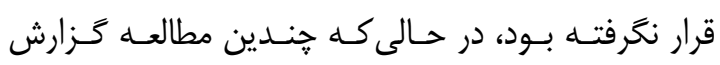

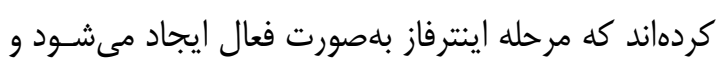

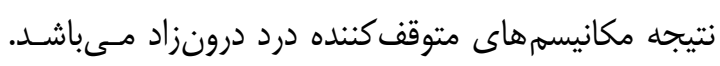

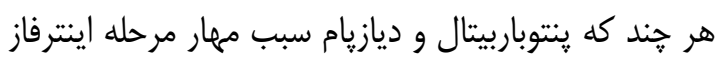

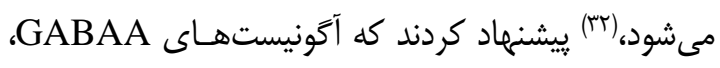

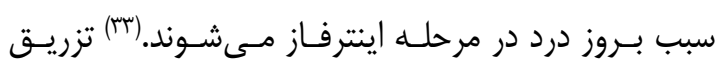

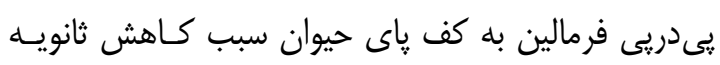


202. doi: 10.1016/j.pneurobio.2009.04.003.

2. Johnson AC, Greenwood-Van Meerveld B. Stress-induced pain: a target for the development of novel therapeutics. J Pharmacol Exp Ther 2014; 351(2): 327-35. doi: 10.1124 jpet.114.218065.

3. Rajaei F, Erami E, Azhdari-Zarmehri H. Effect of exposure to chronic heterogeneous sequential stress during prenatal on formalininduced nociceptive behaviour in adult offspring in rats. J Isfahan Med Sch 2013; 31(256): 1640-8.

4. Ghasemi E, Erami E, Elahdadi Salmani M, Azhdari zarmehri H. Chronic heterogeneous sequential stress increases formalin-induced nociceptive. Physiol Pharmacol 2013; 16(4): 371-9. [In Persian]

5. Parikh D, Hamid A, Friedman TC, Nguyen K, Tseng A, Marquez P, et al. Stress-induced analgesia and endogenous opioid peptides: the importance of stress duration. Eur $\mathbf{J}$ Pharmacol 2011; 650(2-3): 563-7. doi: 10. 1016/j.ejphar.2010.10.050.

6. Ezzatpanah S, Babapour V, Sadeghi B, Haghparast A. Chemical stimulation of the lateral hypothalamus by carbachol attenuated the formalin-induced pain behaviors in rats. Pharmacol Biochem Behav 2015; 129: 10510. doi: 10.1016/j.pbb.2014.12.012.

7. McGaraughty S, Farr DA, Heinricher MM. Lesions of the periaqueductal gray disrupt input to the rostral ventromedial medulla following microinjections of morphine into the medial or basolateral nuclei of the amygdala. Brain Res 2004; 1009(1-2): 223-7. 8. Soliemani N, Moslem A, Shamsizadeh A, Azhdari-Zarmehri H. Administration of orexin receptor 1 antagonist into the rostral ventromedial medulla increased swim stressinduced antinociception in rat. Iran J Basic Med Sci 2016; 19(5): 542-9.
9. Shamsizadeh A, Soliemani N, MohammadZadeh M, Azhdari-Zarmehri H. Permanent lesion in rostral ventromedial medulla potentiates swim stress-induced analgesia in formalin test. Iran J Basic Med Sci 2014; 17(3): 209-15.

10. Haidari-Oranji N, Soleimani N, Sofiabadi M. Effects of lidocaine injections into the rostral ventromedial medulla on nociceptive behviours in hot-plate and formalin tests in rats. Koomesh 2013; 14(4): 490-6. [In Persian]

11. Azhdari-Zarmehri H, Semnanian S, Fathollahi Y, Pakdel FG. Tail flick modification of orexin-a induced changes of electrophysiological parameters in the rostral ventromedial medulla. Cell J 2014; 16(2): 131-40.

12. Jennings EM, Okine BN, Olango WM, Roche M, Finn DP. Repeated forced swim stress differentially affects formalin-evoked nociceptive behaviour and the endocannabinoid system in stress normoresponsive and stress hyper-responsive rat strains. Prog Neuropsychopharmacol Biol Psychiatry 2016; 64: 181-9. doi: 10.1016/ j.pnpbp.2015.05.008.

13. Fossum EN, Lisowski MJ, Macey TA, Ingram SL, Morgan MM. Microinjection of the vehicle dimethyl sulfoxide (DMSO) into the periaqueductal gray modulates morphine antinociception. Brain Res 2008; 1204: 53-8. doi: 10.1016/j.brainres.2008.02.022.

14. Santos NC, Figueira-Coelho J, MartinsSilva J, Saldanha C. Multidisciplinary utilization of dimethyl sulfoxide: pharmacological, cellular, and molecular aspects. Biochem Pharmacol 2003; 65(7): 1035-41. doi: 10.1016/S0006-2952(03) 00002-9.

15. Colucci M, Maione F, Bonito MC, 
Piscopo A, Di Giannuario A, Pieretti S. New insights of dimethyl sulphoxide effects (DMSO) on experimental in vivo models of nociception and inflammation. Pharmacol Res 2008; 57(6): 419-25. doi: 10.1016/j.phrs. 2008.04.004.

16. Rosenstein ED. Topical agents in the treatment of rheumatic disorders. Rheum Dis Clin North Am 1999; 25(4): 899-918, viii doi: 10.1016/S0889-857X(05)70109-5.

17. Azhdari Zarmehri $\mathrm{H}$, Semnanian $\mathrm{S}$, Fathollahi Y, Erami E, Khakpay R, Azizi H, et al. Intra-periaqueductal gray matter microinjection of orexin-A decreases formalin-induced nociceptive behaviors in adult male rats. J Pain 2011; 12(2): 280-7. doi: 10.1016/j.jpain.2010.09.006.

18. Azhdari Zarmehri H, Semnanian S, Fathollahi Y. Comparing the analgesic effects of periaqueductal gray matter injection of orexin A and morphine on formalin-induced nociceptive behaviors. Physiol Pharmacol 2008; 12(3): 188-93. [In Persian]

19. Heidari-Oranjaghi N, Azhdari-Zarmehri $\mathrm{H}$, Erami E, Haghparast A. Antagonism of orexin-1 receptors attenuates swim-and restraint stress-induced antinociceptive behaviors in formalin test. Pharmacol Biochem Behav 2012; 103(2): 299-307. doi: 10.1016/j.pbb.2012.08.007.

20. Coderre TJ, Abbott FV, Sawynok J. Formalin test. In Gebhart, G.F., Schmidt, Robert F. (Eds.) Encyclopedia of Pain. Springer Berlin Heidelberg; 2013.1303-08.

21. Sofiabad M, Heidari N, Ghasemi E, Esmaeili MH, Haghdoost-Yazdi H, Erami E, et al. Assesment of orexin receptor 1 in stress attenuated nociceptive behaviours in formalin test. Physiol Pharmacol 2011; 15(3): 395-402. [In Persian]

22. Valentino RJ, Van Bockstaele E.
Endogenous opioids: the downside of opposing stress. Neurobiol Stress 2015; 1 : 23 32 doi: 10.1016/j.ynstr.2014.09.006

23. Guevara C, Fernandez AC, Cardenas R, Suarez-Roca H. Reduction of spinal PGE2 concentrations prevents swim stress-induced thermal hyperalgesia. Neurosci Lett 2015; 591: 110-4. doi: 10.1016/j.neulet.2015.02. 035.

24. Holden JE, Naleway E. Microinjection of carbachol in the lateral hypothalamus produces opposing actions on nociception mediated by $\alpha 1$-and $\alpha 2$-adrenoceptors. Brain Res 2001; 911(1): 27-36. doi: 10.1016/ S0006-8993(01)02567-7.

25. Heinricher M, McGaraughty S, Tortorici

V. Circuitry underlying antiopioid actions of cholecystokinin within the rostral ventromedial medulla. J Neurophysiol 2001; 85(1): 280-6. doi: 10.1152/jn.2001.85.1.280 26. Azhdari-Zarmehri H, Semnanian S, Fathollahi Y. Orexin-A microinjection into the rostral ventromedial medulla causes antinociception on formalin test. Pharmacol Biochem Behav 2014; 122: 286-90. doi: 10. 1016/j.pbb.2014.03.017.

27. Barragan-Iglesias P, Mendoza-Garces L, Pineda-Farias JB, Solano-Olivares V, Rodriguez-Silverio J, Flores-Murrieta FJ, et al. Participation of peripheral P2Y1, P2Y6 and P2Y11 receptors in formalin-induced inflammatory pain in rats. Pharmacol Biochem Behav 2015; 128: 23-32. doi: 10. 1016/j.pbb.2014.11.001.

28. Haghparast A, Naderi N, Khani A, Lashgari R, Motamedi F. Formalin-induced differential activation of nucleus cuneiformis neurons in the rat: an electrophysiological study. J Pain 2010; 11(1): 32-43. doi: 10. 1016/j.jpain.2009.05.005.

29. Yamato K, Kataoka T, Nishiyama Y, 
Taguchi T, Yamaoka K. Antinociceptive effects of radon inhalation on formalininduced inflammatory pain in mice. Inflammation 2013; 36(2): 355-63. doi: 10. 1007/s10753-012-9554-2.

30. Orru A, Casu MA, Tambaro S, Marchese G, Casu G, Ruiu S. Withania somnifera (L.) Dunal root extract alleviates formalin-induced nociception in mice: involvement of the opioidergic system. Behav Pharmacol 2016; 27(1): $\quad 57-68$. doi: 10.1097/FBP. 0000000000000195.

31. Azhdari-Zarmehri H, Mohammad-Zadeh M, Feridoni M, Nazeri M. Termination of nociceptive bahaviour at the end of phase 2 of formalin test is attributable to endogenous inhibitory mechanisms, but not by opioid receptors activation. Basic Clin Neuro sci 2014; 5(1): 48-54.
32. Fischer M, Carli G, Raboisson P, Reeh P. The interphase of the formalin test. Pain 2014; 155(3): 511-21. doi: 10.1016/j.pain. 2013.11.015.

33. Potes CS, Neto FL, Castro-Lopes JM. Inhibition of pain behavior by $\mathrm{GABA}(\mathrm{B})$ receptors in the thalamic ventrobasal complex: effect on normal rats subjected to the formalin test of nociception. Brain Res 2006; 1115(1): 37-47. doi: 10.1016/j.brainres. 2006.07.089.

34. Hough LB, Nalwalk JW, Yang W, Ding $X$. Significance of neuronal cytochrome P450 activity in opioid-mediated stress-induced analgesia. Brain Res 2014; 1578: 30-7. doi: 10.1016/j.brainres.2014.07.007. 